\title{
Correction
}

\section{Correction to: The effect of time series distance functions on functional climate networks}

Leonardo N. Ferreira ${ }^{1,2,3, a}$, Nicole C. R. Ferreira ${ }^{4}$, Elbert E. N. Macau ${ }^{1,5}$, and Reik V. Donner ${ }^{3,6}$

${ }^{1}$ Associated Laboratory for Computing and Applied Mathematics, National Institute for Space Research, Av. dos Astronautas, 1758, Jardim da Granja, São José Dos Campos, SP 12227-010, Brazil

2 Department of Physics, Humboldt University, Newtonstraße 15, 12489 Berlin, Germany

${ }^{3}$ Research Department IV-Complexity Science, Potsdam Institute for Climate Impact Research (PIK)-Member of the Leibniz Association, Telegrafenberg A56, 14473 Potsdam, Germany

${ }^{4}$ Center for Weather Forecast and Climatic Studies, National Institute for Space Research, Rodovia Presidente Dutra, Km 40, Cachoeira Paulista, SP 12630-000, Brazil

${ }^{5}$ Institute of Science and Technology, Federal University of São Paulo, Av. Cesare Monsueto Giulio Lattes, 1201-Eugênio de Melo, São José dos Campos, SP, Brazil

${ }^{6}$ Department of Water, Environment, Construction and Safety, Magdeburg-Stendal University of Applied Sciences, Breitscheidstr. 2, 39114 Magdeburg, Germany

Published online 1 December 2021

() EDP Sciences, Springer-Verlag GmbH Germany, part of Springer Nature 2021

\section{Correction to: Eur. Phys. J. Spec. Top.}

https://doi.org/10.1140/epjs/s11734-021-00274-y

Due to technical problems this article has been pub-

The original article has been corrected.

lished before corrections were implemented.

The original article can be found online at https://doi.org/ 10.1140/epjs/s11734-021-00274-y.

\footnotetext{
${ }^{\mathrm{a}}$ e-mail: ferreira@leonardonascimento.com (corresponding author)
} 